\title{
Pharmacovigilance Practices: Knowledge and Attitudes among the Healthcare Professionals at the Volta Regional Hospital of Ghana Amedome $\mathrm{SN}^{1 *}$ and Dadson $\mathrm{BA}^{2}$
}

${ }^{1}$ Department of Multidisciplinary Studies, Ho Technical University, Ghana

${ }^{2}$ Volta Regional Office, Food and Drugs Authority, Ghana

\begin{abstract}
Pharmacovigilance since its inception has been the global medicine safety monitoring tool by all World Health Organization member states. Ghana joined the program as the $65^{\text {th }}$ member in 2001 . Pharmacovigilance has mainly relied on spontaneous reports of adverse drug reactions from healthcare professionals. However, under reporting has been reported to be a major challenge. The success of the PV system in Ghana depends greatly on the understanding, active involvement and practices among the country's healthcare professionals The study evaluated the pharmacovigilance practices among the healthcare professionals at the Volta Regional Hospital, Ho, by assessing their knowledge, attitudes and practices towards the program. A descriptive cross-sectional design was used and a 27 -item pre-tested self-administered questionnaire as the research instrument. Convenient and judgmental sampling techniques were used to select an estimated sample of 145 representing, $68.1 \%$ of the targeted population. Data was processed and analyzed by the use of Statistical Package for Social Sciences (SPSS) version 20. Using descriptive statistics, frequencies were used to attain the individual and average percentages of responses. High level of awareness (doctors $88 \%$, pharmacists $92.2 \%$ and nurses $78 \%$ ) and positive attitude (doctors $72.4 \%$, pharmacists $83.8 \%$ and nurses 68.2 ) among the respondents on pharmacovigilance was observed. The level of practice was observed to be relatively lower, especially among the doctors and the nurses. As low as $16.7 \%$ and $24 \%$ of the doctors and the nurses has ever reported ADRs by the use of the Blue form. Continual training on the essence and the use of the reporting forms with increased availability and accessibility of the reporting forms at all departments/units of the hospital coupled with regular public education on ADR reporting are recommended interventions.
\end{abstract}

Keywords: Pharmacovigilance; Knowledge; Attitudes; ADRs; Health care

\section{Introduction}

The use of medicines and medicinal products form a great part in the delivery of quality health care in any country. The use of pharmaceutical preparations has become one of the most fast growing components of global health care expenditure. It is shown to account for nearly $30 \%$ of the health budgets in most countries. According to the $2^{\text {nd }}$ edition [1], drugs are estimated to constitute about $60 \%$ to $80 \%$ of the national health care cost in Ghana. In the health care delivery system, drugs are much useful in promoting health, preventing and managing diseases. However, some form of adverse drug reactions occur in most patients when taking medicines. As pointed out by the Committee on Medicine Safety, established in the UK after the thalidomide disaster in the early 1960's in its last report (for 1969 and 1970) that, "no drug which is pharmacologically effective is without hazard and that not all hazards can be known before a drug is marketed", there has been increased concerns about the safety of medicines in use [2].

The international medicine safety monitoring system (pharmacovigilance) engineered by the World Health Organization (WHO) since 1961 is basically aimed at collaborative monitoring, reporting and preventing such avoidable ADRs between member states. Pharmacovigilance (PV) has been defined by the WHO as "the science and activities relating to detection, assessment, understanding and prevention of ADRs or any other drug related problem" [3]. When Pharmacovigilance is practiced effectively as an essential arm of patient care, the risks and the risk factors associated to the use of medicines can be identified in the shortest possible time and as such prevent or minimize the harm related to ADRs. Good pharmacovigilance practice can generate the evidence that will inspire public confidence and trust in the health care delivery system [3].
Ghana joined the WHO program for international drug safety monitoring in the year 2001 [4]. Although Ghana is participating in the program, its contribution to the UMC database is comparatively little. The Issue 3 (2015) of the Food and Drugs Authority's Druglens Newsletter reveals that, reports on ADRs in Ghana have mainly been received from health care providers since Ghana joined the global drug safety monitoring system. The same newsletter also reports that, within a year, Ghana's National Pharmacovigilance Centre receives on the average 12 ADR reports per 1,000,000 Ghanaians which is less than the WHO recommendation that a fully functional PV system should receive 200 to 250 reports per million populations per year instead of the WHO recommended 5,000 approximates per year. This number is currently not being achieved due to gross underreporting.

The resultant effect of this high level of under reporting is the greater possibility that safety issues regarding medicine use in Ghana will go undetected and negatively stain the country's attempt to deliver quality health care. It appears knowledge, attitude and practice regarding pharmacovigilance and ADR reporting among healthcare professionals have not been extensively studied in Ghana.

*Corresponding author: Sedem Nunyuia Amedom, Lecturer/Counseling Officer Department of Multidisciplinary Studies, Ho Technical University, P.O. Box hp217 Ho Volta Region 233, Ghana, Tel: +233244055763/233201204971; E-mail: samedome@htu.edu.gh

Received: May 12, 2017; Accepted June 20, 2017; Published June 27, 2017

Citation: Amedome SN, Dadson BA (2017) Pharmacovigilance Practices: Knowledge and Attitudes among the Healthcare Professionals at the Volta Regional Hospital of Ghana. J Pharmacovigil 5: 229. doi:10.4172/2329-6887.1000229

Copyright: (c) 2017 Amedome SN, et al. This is an open-access article distributed under the terms of the Creative Commons Attribution License, which permits unrestricted use, distribution, and reproduction in any medium, provided the original author and source are credited. 
The study therefore, sought to evaluate the knowledge levels and attitudes towards pharmacovigilance activities among the healthcare professionals in the Volta Regional Hospital in Ho with the aim of promoting quality health care delivery in the country through medicine safety monitoring.

\section{Pharmacovigilance in Ghana}

Medicine safety monitoring in Ghana is regulated by the Food and Drugs Authority (FDA) which also holds the National Pharmacovigilance Centre. The centre receives spontaneous reports mainly from health workers for causality assessment and onward reporting to the WHO Database. The system of reporting of ADRs is by the use of the FDA's ADR Form (the Blue Form), the Tuberculosis Form (TB Form) and the Adverse Event Following Immunization (AEFI) form. The pharmacovigilance system in Ghana is as depicted in the Figure 1. A review of the ADR reporting pattern among some health care facilities in the Volta Region of Ghana, as shown in the Table 1 reveals the nature of under-reporting of ADRs in these facilities.

Healthcare professionals' knowledge of the safety monitoring system has been shown to influence their active participation in the program. In studying the knowledge of health workers towards pharmacovigilance, most of the studies concentrated on the following knowledge areas: knowledge of the pharmacovigilance systems in their host nations, the main purpose of pharmacovigilance, the role of the healthcare professional in the program, the reporting tool to be used and information to be provided in the ADR reporting scheme.

For instance, Green et al. [5] found in their studies involving hospital pharmacists that majority of the participant $(97.0 \%)$ had knowledge about the UK's safety monitoring system (the Yellow Card system) for reporting ADRs. The results from their studies also shown that $97.7 \%$ of the pharmacists knew all reactions are to be reported, especially for newly marketed products. These results are consistent with those reported for doctors by Belton et al.; Bateman et al. $[6,7]$.
Also, Chopra et al. [8] in a study conducted in India found that $74.4 \%$ of the doctors in the study had the knowledge that they should report ADRs to new drugs whiles $15 \%$ and $10.6 \%$ knew that they should report serious reactions and unusual reactions respectively. This is revealing and has implications for the present studies in Ghana. In the African context, results from a study conducted in a Nigerian teaching hospital showed that, the respondents exhibited low levels of awareness towards pharmacovigilance and ADR reporting using the NAFDAC Yellow Form. The study found that more than half of the respondents had no knowledge of the NAFDAC yellow form. The low level of awareness in the study was attributed to the lack of training and sensitization and as such, the study recommended more educational interventions [9].

Studies that looked at the attitudes of health workers towards pharmacovigilance and ADR reporting primarily considered issues related to health workers' opinion about ADR reporting and the factors that affect the attitudes towards the program (factors that either encourage or hinder ADR reporting). The healthcare professionals studied at a hospital in Nepal had relatively better attitudes towards ADR reporting [10]. Majority of the respondent in that study believed that ADR monitoring was essential to the safety of patients. Lack of time to report ADRs has also been cited as one of the major hindrances to passive pharmacovigilance $[8,11,12]$.

A recent study by Sabblah et al. [13] in the Greater Accra Region of Ghana to assess the ADR reporting among doctors in the region, reported low levels of ADR reporting by the doctors, although almost all the participant (96.4\%) in the study exhibited some level of knowledge and agreed that it is their professional responsibility to report ADRs. This study however did not assess the ADR reporting practices by other healthcare professionals (i.e., Nurses and Pharmacist) but recognized the important roles these other professionals need to play to enhance the attainment of the aims of the pharmacovigilance program in Ghana. Several models have been developed and used to assess the level to which people carry out programs and policies as they are mandated to do.

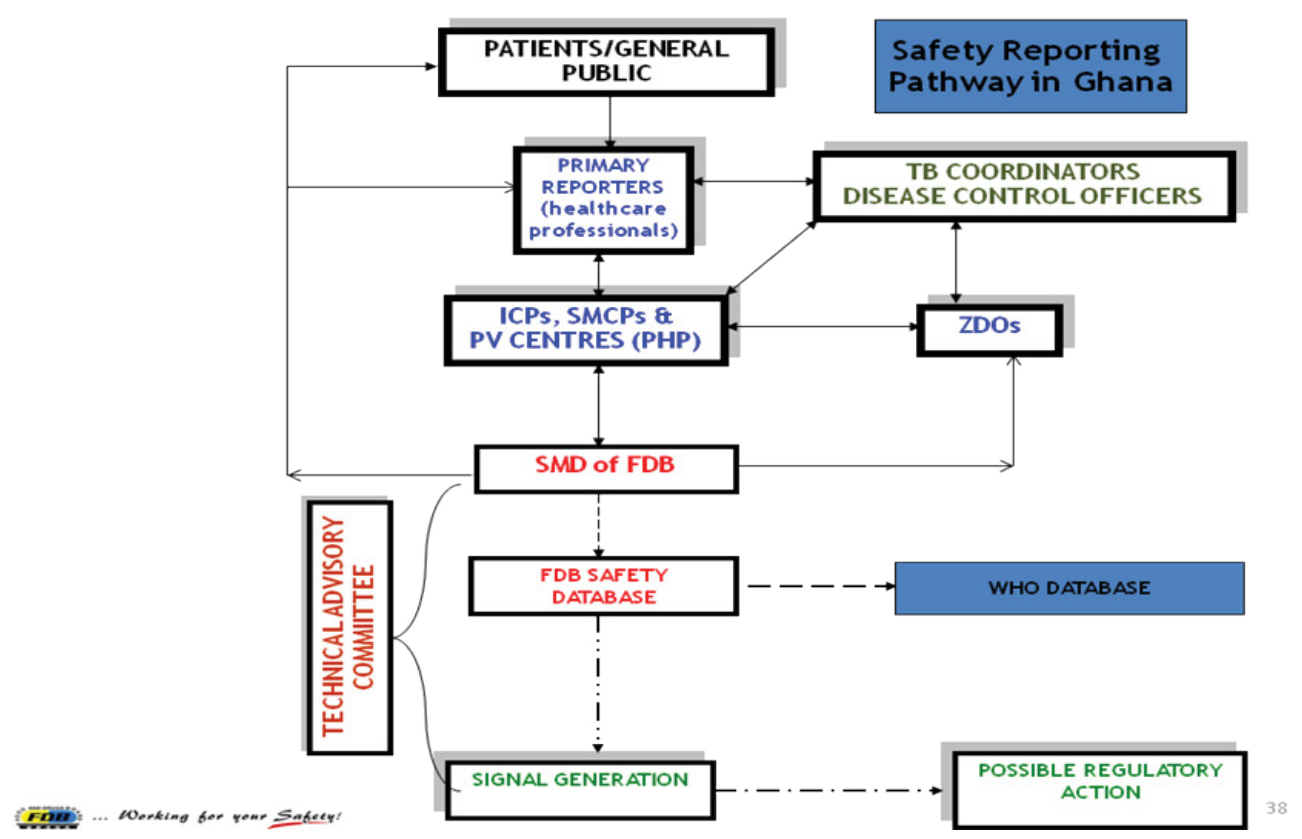

Figure 1: Medicine safety reporting pathway in Ghana [4]. 
This study used the Knowledge, Attitude and Practice (KAP) survey model to evaluate the pharmacovigilance activities among the health workers at the Volta Regional Hospital by assessing their knowledge, attitude and practice towards the program. The KAP model is widely used because it is an effective tool to identify the barriers to the execution of policies, and to give recommendations based on specific interventions.

The ability of people to perform certain activities is a function of their knowledge and attitudes towards such activities. The frame work underpinning the use of this model for the study is as shown in the Figure 2, an adopted KAP Instrument Design based on Bennett's Change Model.

\section{Study Design}

In order to achieve the objectives of the study a descriptive crosssectional research design was employed because knowledge of any subject and the attitudes and practices towards the subject tends to change over time. Hence determination of such variables among the chosen population had to be done at a particular point in time.

\section{Study site and study population}

The Volta Regional Hospital (VRH) in Ho in the Volta Region of Ghana was chosen as the study site for the study. The hospital serves as the referral site for all the hospitals and sub-health facilities in the region, as well as providing daily health services to the Ho Municipality. It is assumed that this health institution has the greater probability that patients with varying degrees of ADRs will be seen by the health workers. This is because the hospital uses wider range of pharmaceutical classes of medicines and also serves patients with various levels of disease severity.
The study population were the health workers at the Volta Regional Hospital. The total number of staff at the hospital stood at 585 in June 2016 with over $50 \%$ being medical personnel and the rest being nonmedical officers (VRH Human Resource Department, June 2016). The medical officers include doctors, nurses, pharmacists, pharmacy technologists, dispensing assistants, lab technologist, nutritionists, radiographers, etc. The non-medical officers include personnel at the administration, human resource, records, finance, security and support staff. Though medical personnel are most likely to report ADRs, certain cadre of them like lab technologists, may not be in positions to identify and detect ADRs as they do not interact directly with patients on the use of medicines. Hence the study population chosen for the study included cadres of health workers at the hospital that directly interact with patients and are in positions to detect and report ADRs such as nurses, doctors, pharmacists, pharmacy technologists and dispensing technologists. The distribution of these health workers as at June 2016 is as shown in the Table 2.

\section{Study unit, sampling technique and sample size}

For the purpose of the research, the study unit included in the study involved healthcare professionals that met the following conditions:

- A healthcare professional that has clinically practiced permanently for not less than a year at the time of the study in his or her profession.

- A health care professional that interacts directly with patients in relation to medicine use and is in a position to detect and report ADRs.

The exclusion criteria were based on the under listed factors:

- Healthcare professionals that have not clinically practiced permanently for up to a year in his or her profession.

\begin{tabular}{|c|c|c|c|c|c|c|c|c|}
\hline & 2007 & 2008 & 2009 & 2010 & 2011 & 2012 & 2013 & Total \\
\hline Volta Regional Hospital & 12 & 0 & 1 & 4 & 3 & 7 & 1 & 28 \\
\hline Ho Municipal Hospital & 9 & 0 & 0 & 0 & 3 & 5 & 0 & 17 \\
\hline Adidome Govt. Hospital & 0 & 0 & 1 & 0 & 0 & 0 & 0 & 1 \\
\hline Miracle Life Clinic & 0 & 0 & 2 & 0 & 1 & 3 & 0 & 6 \\
\hline Comboni Hospital & 0 & 0 & 0 & 3 & 0 & 0 & 11 & 14 \\
\hline Jasikan District Hospital & 0 & 0 & 0 & 1 & 0 & 0 & 0 & 1 \\
\hline Sogakofe District Hospital & 0 & 0 & 0 & 0 & 19 & 8 & 5 & 32 \\
\hline Akatsi District Hospital & 0 & 0 & 0 & 0 & 3 & 1 & 0 & 4 \\
\hline Keta Municipal Hospital & 0 & 0 & 0 & 0 & 2 & 1 & 4 & 7 \\
\hline Ho Polyclinic & 0 & 0 & 0 & 0 & 0 & 0 & 1 & 1 \\
\hline Saint Anthoby Hospital & 0 & 0 & 0 & 0 & 0 & 0 & 2 & 2 \\
\hline
\end{tabular}

Table 1: ADR reporting trend among some health care institutions in the Volta Region from 2007 to 2013 [4].

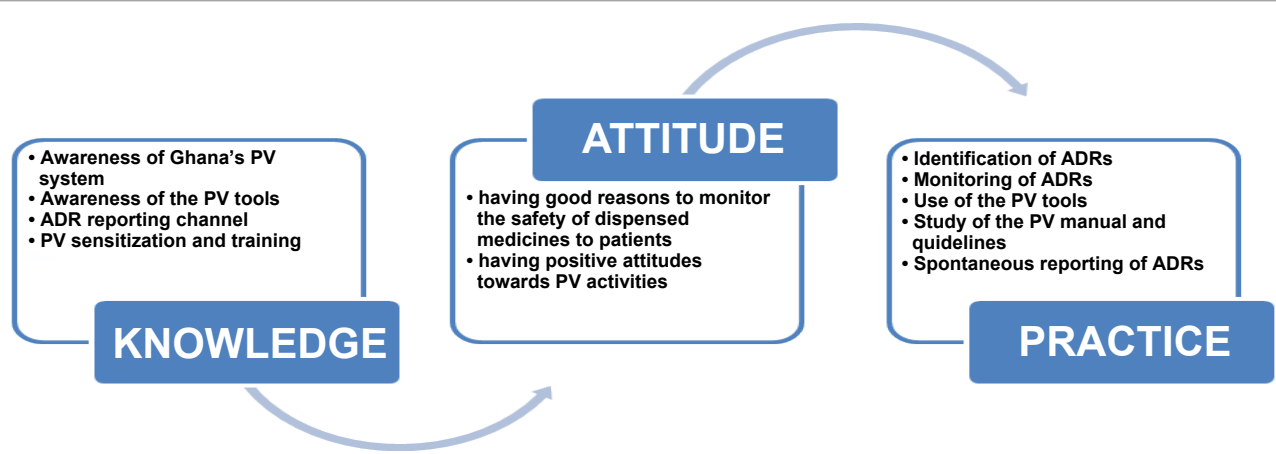

Figure 2: Conceptual frame work adopted for the survey based on the Bennett's change model. 
- Healthcare professionals that do not interact directly with patients in relation to medicine use and are not in positions to report ADRs.

Convenient and judgemental sampling techniques were employed to select the survey respondent. An estimated judgemental sample of 145 was involved in the study, representing $68.1 \%$ of the targeted population.

\section{Research instrument}

The research instrument employed for the study was a 27 -item self-administered questionnaire containing both open-ended and closed-ended questions and anonymous based. The questionnaire was made anonymous to give the advantage to result in more likely honest responses as the items that assessed the attitude of the healthcare professional towards pharmacovigilance was of personal in nature.

\section{Data processing and analysis}

Data was collected using a structured pre-tested questionnaire. Predominantly, the questionnaires were given to the prospective healthcare professionals to be returned in a days' time. Respondents who were ready and willing to provide immediate responses were engaged in face to face interview sections. Data was checked for the completeness, quality and accuracy of the responses.

Data was coded and analyzed by the use of the Statistical Package for Social Sciences (SPSS) version 20. Using descriptive statistics, frequencies were used to attain the individual percentages of responses. Average percentages were calculated to determine the level of knowledge, attitude and practice of pharmacovigilance among the study respondents.

\section{Results and Discussion}

The general purpose of this study was to evaluate the levels of knowledge and attitudes towards pharmacovigilance activities among healthcare professionals at the Volta Regional Hospital, Ho. Since the fundamental activity of the practice of pharmacovigilance is the reporting of ADRs, it is important to check the knowledge, attitude and practice of healthcare professionals towards PV program. The findings obtained from the study are presented and discussed below. In presenting the results from the study, frequency tables, and bar graphs were used.

The respondents of the study included doctors, pharmacists (including pharmacy technicians and dispensing assistants), and nurses of the hospital, giving a total of 145 respondents from the hospital. All the questionnaires administered to the study respondents were completed and returned giving a response rate of $100 \%$. The distribution of study respondents by cadre is presented in the Table 3 .

The number of doctors included in the study was 30 , of which $23(76.7 \%)$ were males and $7(23.3 \%)$ were females. Sixteen $(53.3 \%)$ were between the ages of 34-41 years, 11 (36.7\%) between 26-33 years, $2(6.7 \%)$ between $18-25$ years, and $1(3.3 \%)$ was 42 and above. Ten (33.3\%) had worked between 1-4 years, 17 (56.7\%) between 5-10 years, and the remaining 3 (10\%) had worked 10 years and over. The departments in which they worked included but not limited to OPD, female/male wards, E.N.T, emergency unit, among others. The number of pharmacist included in the study was 15 . The number of males was $5(33.3 \%)$ and the females were $10(66.7 \%)$. One (6.7\%) was between the age group of $18-25$ years, $5(33.3 \%)$ between $26-33$ years, another $5(33.3 \%)$ were 42 and above, and the remaining $4(26.7 \%)$ were between $34-41$ years. One had worked between 1-4 years, 11 (73.3\%) between 5-10 years, and 3 (20.2\%) had worked 10 years and above. These respondents worked at the OPD pharmacy and the Accident and Emergency Pharmacy.

A total of 100 nurses were included in the study. Majority $(n=75)$ were females representing $75 \%$ and 25 (25\%) were males. 24 were between the ages of $18-25$ years, 51 were between $26-33$ years, 15 were between $34-41$ years, and 10 were 42 years and above. The nurses worked at but not limited to the OPD, the wards (both male and female), accident and emergency, eye clinic and ENT units. The level of knowledge of pharmacovigilance among healthcare professionals at the Volta Regional Hospital, Ho.

The first specific objective of the study was to assess the level of knowledge of pharmacovigilance practices among healthcare professionals at the Volta regional hospital. Table 4 shows the findings of the responses when respondents were asked to provide correct responses to the items assessing their level of knowledge towards pharmacovigilance and ADR reporting.

From the responses received, all the doctors had heard of pharmacovigilance in Ghana. Majority (83.3\%) was also aware of ADR reporting and monitoring system in the country. 27 (90\%) indicated pharmacovigilance was to identify the safety of drugs. All the doctors also knew the location of the national pharmacovigilance centre. Also, majority of doctors $(20,66.7 \%)$ are of the view that, the healthcare professional is to report ADRs to the regulatory agency (FDA) in Ghana. This according to 28 (93.3\%) was to be done using the FDA's blue form.

Findings from the study revealed that all the respondent pharmacists $(n=30,100 \%)$ had heard of pharmacovigilance and also aware of ADR reporting and monitoring. Majority $(n=13,86.7 \%)$ of them correctly indicated identification of drug safety as the main purpose of pharmacovigilance. All respondents agreed to the head office of the FDA being the reporting centre for pharmacovigilance in Ghana. $11(73.3 \%)$ of respondents are of the view that, the main role of healthcare professionals in pharmacovigilance is to report ADRs to the regulatory agency and $14(93.3 \%)$ indicated FDA's ADR form is to be used in reporting ADR cases.

Out of 100 nurses, 90 (90\%) had heard of pharmacovigilance. $76(76 \%)$ were also aware of ADR reporting and monitoring system in the country. $74(74 \%)$ of respondent stated identification of safety of drugs as the most important purpose of pharmacovigilance.78 (78\%) agreed with the head office of FDA to be the national pharmacovigilance

\begin{tabular}{|l|c|c|}
\hline Cadre & $\begin{array}{c}\text { Staff in post, } \\
\text { June 2016 }\end{array}$ & $\begin{array}{c}\text { Percentage } \\
\text { (\%) }\end{array}$ \\
\hline Doctors (Including specialist, Dentists) & 37 & 17.1 \\
\hline $\begin{array}{l}\text { Pharmacists (Including pharmacy technologists and } \\
\text { Dispensing technicians) }\end{array}$ & 17 & 7.9 \\
\hline Nurses & 162 & 75.0 \\
\hline Total & 216 & 100.0 \\
\hline
\end{tabular}

Table 2: Distribution of selected cadres of health workers in the VRH in June 2016

\begin{tabular}{|c|c|c|}
\hline Cadre of profession & Frequency & Percentage (\%) \\
\hline Doctors & 30 & 20.7 \\
\hline Pharmacist & 15 & 10.3 \\
\hline Nurses & 100 & 70.0 \\
\hline Total & 145 & 100 \\
\hline
\end{tabular}

Table 3: Distribution of respondents by cadre of profession. 
reporting centre. Majority (72) also stated reporting all observed/ encountered ADRs to regulatory agency as their role and $78(78 \%)$ of respondents indicated FDA's blue form is to be used in reporting ADRs. The average percentage of the respondents on the level of knowledge towards pharmacovigilance and ADR reporting is as presented in the Figure 3 .

The healthcare professional's knowledge of the safety and monitoring system of PV has been found to influence their active participation in pharmacovigilance. From the results presented above, the respondent doctors at the hospital can be said to have good knowledge of pharmacovigilance. All the doctors included in the study were knowledgeable of PV and majority were also aware of the ADR reporting and monitoring system in Ghana. Majority also knew ADRs are to be reported using FDA's blue form in Ghana. Pharmacists interviewed were also knowledgeable of PV. They had all heard of PV and are aware of ADR reporting and monitoring system in Ghana. Majority also stated the purpose of ADR was to identify safety of drugs and also knew FDA head office to be the national PV centre. Majority of nurses had also heard of PV and are aware of ADR reporting and monitoring system in Ghana. Most of them also stated identifying safety of drugs as the main purpose of pharmacovigilance.

Generally it can be deduced that the respondents involved the present study were knowledgeable about the pharmacovigilance program. This can be attributed to the fact that more of the sensitization and training on the PV program by the country's National
Pharmacovigilance Centre has over the years been carried out in most Government health facilities [3]. However, with an average percentage (Ave \%) of 92.2\% (Figure 3) for the surveyed pharmacists related to their knowledge towards pharmacovigilance and ADR reporting, this cadre of healthcare professionals can comparatively be said to be more knowledgeable than the doctors (Ave $\%=88.8 \%$ ) and the nurses (Ave $\%=78 \%)$.

Result from the present study is in concordance with earlier studies that also reported high knowledge levels for respondents. In the UK, Food and Drugs Authority [4] reported that majority (97.0\%) of the studied respondent had knowledge about the UK's safety monitoring system (the Yellow Card system) [14]. Also, found out that the respondents were knowledgeable about their country's pharmacovigilance system when as high as $99.6 \%$ of the respondents in their study were reported to be aware of their national ADR reporting scheme. More than half of the respondents involved in studies carried out by Chopra et al.; Ting et al.; Vessal et al. $[8,15,16]$ were also aware of the existent of their countries' National Pharmacovigilance Centres which are responsible for collecting ADR reports. The present study is again in concordance with the study conducted in the Greater Accra Region of Ghana whish reported that almost all the respondents (96.4) in the study were knowledgeable about PV [13].

The high level of knowledge of PV and ADR reporting recorded in the present study however, contrast's results from some earlier studies like the study by Ting et al. [15] in Iran. In their study, the respondents

\begin{tabular}{|c|c|c|c|c|c|c|c|}
\hline \multirow{2}{*}{ Questions } & \multirow{2}{*}{ Correct Responses } & \multicolumn{2}{|c|}{ Doctors $(n=30)$} & \multicolumn{2}{|c|}{ Pharmacists $(n=15)$} & \multicolumn{2}{|c|}{ Nurses $(u=100)$} \\
\hline & & Freq. & $\%$ & Freq. & $\%$ & Freq. & $\%$ \\
\hline Have you heard of PV & Yes & 30 & 100 & 15 & 100 & 90 & 90 \\
\hline $\begin{array}{l}\text { Awareness of ADR reporting and } \\
\text { monitoring system in Ghana }\end{array}$ & Yes & 25 & 83.3 & 15 & 100 & 76 & 76 \\
\hline Purpose of pharmacovigilance & To identify safety of drugs & 27 & 90 & 13 & 86.7 & 74 & 74 \\
\hline Location of Ghana pharmacovigilance & Head office of the FDA & 30 & 100 & 15 & 100 & 78 & 78 \\
\hline $\begin{array}{l}\text { Main role of healthcare professionals in } \\
\text { pharmacovigilance }\end{array}$ & $\begin{array}{c}\text { Reporting ADRs to regulatory } \\
\text { Agency }\end{array}$ & 20 & 66.7 & 11 & 73.3 & 72 & 72 \\
\hline In Ghana, the reporting of ADRs is done by the use of the & FDA's ADR reporting form & 28 & 93.3 & 14 & 93.3 & 78 & 78 \\
\hline Average $\%$ & - & \multicolumn{2}{|c|}{88.8} & \multicolumn{2}{|c|}{92.2} & \multicolumn{2}{|c|}{78} \\
\hline
\end{tabular}

Table 4: Correct responses to the items to the assessing respondents level of the knowledge of PV.

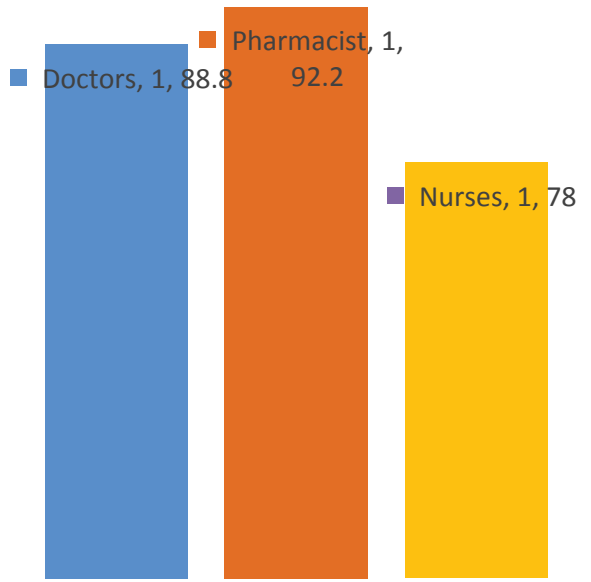

Doctors

Pharmacist

Nurses

Figure 3: Percentage of average knowledge of respondents on pharmacovigilance. 
knowledge on the purpose of PV was found to be low with less than half $(49 \%)$ of the respondents knowing that one of the purpose of the program is to identify the safety of medicines approved for use [16]. Training on the essence of PV and ADR reporting was suggested to improve the knowledge of the study respondents. In India, Rehan et al. [17] reported similar low knowledge levels in their studies. A similar study in Malaysia it was reported that about $40 \%$ of the respondents did not know about the existence of the national reporting system for ADRs [18]. Similar results have also been reported in China where $71 \%$ of the healthcare professionals studied did not have knowledge about the country's ADR reporting procedure [19]. In a Nigerian teaching hospital, Aziz et al. [8] found that the participants in their study exhibited low levels of awareness towards PV and ADR reporting using the NAFDAC Yellow Form with more than half having no knowledge of the NAFDAC Yellow Form. The low level of awareness in the study was attributed to the lack of training and sensitization and as such, much educational interventions were recommended.

Running through all these studies is the suggestion of educational interventions to improve upon the knowledge of healthcare professionals in relation to the essence of $\mathrm{PV}$ and ADR reporting, the existence of national procedures for ADR reporting, the role of the HCP in program and the tools for reporting. Such interventions can also be said to be valid for the participants in the present study to continually improve upon their knowledge, especially knowledge areas relating to the roles of the HCP in the PV program. This is necessary because, though on the average the overall knowledge levels of the study participants were high, the participants scored comparatively lower marks (Table 4) in responding correctly to the item that asked about the main role of the HCP in PV. Such educational interventions are essential because very high levels of PV knowledge are needed to complement the attainment aims of the program. This also will help curb situations where HCP professionals at the hospital may observe/encounter a patient experience an ADR and not deem it necessary to report. Attitude of Respondents towards Pharmacovigilance. The second specific objective of the study was to assess the attitude of the respondents towards PV. Table 5 shows the findings of the responses when respondents were asked to respond to the items in the questionnaire that sought to assess their attitudes towards pharmacovigilance and ADR reporting.

Out of a total of 30 doctors, 28 (93.4\%) agreed that, the reporting of ADRs in hospitals in not limited to pharmacists only, but all healthcare professionals. Also, 23 (76.7\%) further agreed ADR reporting was a professional obligation. $26(86.7 \%)$ also view ADR reporting as necessary. When asked whether non-remuneration for reporting discouraged healthcare professionals from reporting ADRs, 17 (56.7\%) disagreed. Respondents were also asked whether the lack of time to report $\mathrm{ADR}$ was a discouraging factor to ADR reporting. From the responses less than half $(n=11,36.7 \%)$ of the doctors disagreed with lack of time to report ADR cases being a discouraging factor to ADR reporting with majority $(n=19,63.3 \%)$ of them. Concerning ADR reporting and patient safety, $28(93.3 \%)$ of the doctors agreed reporting ADRs will help increase patient safety in relation to medicine. Finally, respondents were also asked of their willingness to report ADRs when encountered. From the responses received, 19 (63.3\%) of the doctors agree to willingly report ADRs when encountered.

Majority of pharmacists $(\mathrm{n}=14,93.3 \%)$ agreed that, all healthcare professionals are responsible for the reporting of ADRs in the hospital. Also, $10(66.7 \%)$ agreed reporting ADR is a professional obligation. 14 (93.3\%) also agreed to ADR reporting being necessary. 9 (60.3\%) disagreed with non-remuneration being a reason for not reporting ADRs. $11(73.2 \%)$ indicated lack of time to report ADRs did not discourage them from reporting ADRs. All the pharmacists agreed reporting ADRs will increase patient safety in relation to medicine and are also willing to always make ADR reports when encountered.

From the responses received from 100 nurses involved in the study, $74 \%$ saw ADR reporting as the duty of all healthcare professionals. $72 \%$ also thought ADR reporting was a professional obligation. When asked whether reporting ADR was necessary, $80 \%$ agreed with ADR reporting to be necessary. Less than half (45\%) of the nurses disagreed that non-remuneration of ADR reporting being a discouraging factor in reporting ADRs. With regards to ADR reporting increasing patient safety in relation to medicine, $87 \%$ agreed ADR reporting will increase patient safety. Also, $81 \%$ of the nurses expressed their willingness to always make ADR reports when encountered.

The average percentage of the respondents having positive attitude towards PV and ADR reporting is as presented in the Figure 4. Even with high knowledge levels, healthcare professionals require positive attitudes towards pharmacovigilance to enhance ADR reporting. Such positive attitudes include the view of the medicine safety monitoring system as an ethical and professional thing to do as well as being part of the health care delivery system.

Results from the present study suggest that, in general the participants have positive perceptions (attitudes) towards PV and ADR reporting as evident in the calculated average percentages (doctors $72.4 \%$, pharmacists $83.8 \%$ and nurses 68.2 ) in Figure 4. This is similar to the study of healthcare professionals at a hospital in Nepal which revealed that the respondents had relatively better attitudes towards ADR reporting [10]. Majority of all the cadres of the HCP studied had positive opinions about PV program and ADR reporting. 76.7\%, 66.7\% and $72 \%$ of the doctors, pharmacists and nurses respectively had the

\begin{tabular}{|c|c|c|c|c|c|c|c|}
\hline \multirow{2}{*}{ Questions } & \multirow{2}{*}{ Correct Responses } & \multicolumn{2}{|c|}{ Doctors $(n=30)$} & \multicolumn{2}{|c|}{ Pharmacists $(n=15)$} & \multicolumn{2}{|c|}{ Nurses $(n=100)$} \\
\hline & & Freq. & $\%$ & Freq. & $\%$ & Freq. & $\%$ \\
\hline $\begin{array}{l}\text { All healthcare professionals are responsible for the reporting of ADRs in } \\
\text { a hospital and not only pharmacists }\end{array}$ & Agree & 28 & 93.4 & 14 & 93.3 & 74 & 74 \\
\hline Do you think reporting of ADRs is a professional obligation & Agree & 23 & 76.7 & 10 & 66.7 & 72 & 72 \\
\hline Do you think reporting of ADRs is necessary & Agree & 26 & 86.7 & 14 & 93.3 & 80 & 80 \\
\hline Non-remuneration for reporting discourages you from reporting ADRs & Disagree & 17 & 56.7 & 9 & 60.3 & 45 & 45 \\
\hline Lack of time to report ADR discourages you from reporting & Disagree & 11 & 36.7 & 11 & 73.2 & 39 & 39 \\
\hline $\begin{array}{l}\text { Do you think reporting ADRs will increase patient safety in relation to } \\
\text { medicine }\end{array}$ & Agree & 28 & 93.4 & 15 & 100 & 87 & 87 \\
\hline Are you willing to always make ADR reporting when encountered & Agree & 19 & 63.3 & 15 & 100 & 81 & 81 \\
\hline Average \% & & \multicolumn{2}{|c|}{72.4} & \multicolumn{2}{|c|}{83.8} & \multicolumn{2}{|c|}{68.2} \\
\hline
\end{tabular}

Table 5: Attitudes of respondents towards pharmacovigilance and ADR reporting. 


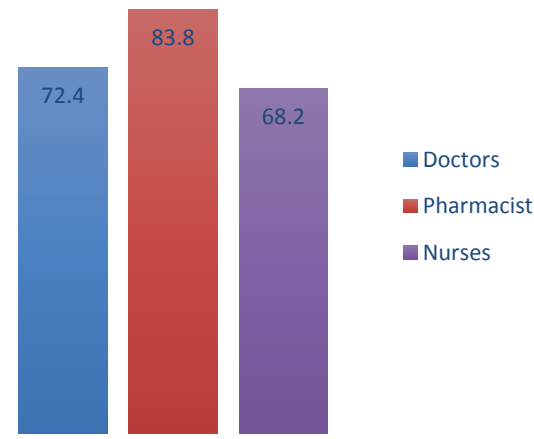

Figure 4: Percentages of average positive attitudes of respondents towards pharmacovigilance.

view that ADR reporting is a professional obligation and part of clinical care. The view that the practice of PV is a professional obligation will have moral binding to the HCP and ethical issues. The results from the present study also shows that majority (doctors $86.7 \%$, pharmacists 93.3\% and nurses $80 \%$ ) of all the cadres of the HCP studied opines that PV and ADR reporting is necessary. Majority (doctors 93.4\%, pharmacists $100 \%$ and nurses $87 \%$ ) also positively had the view that reporting of ADRs by HCP will increase patient safety in relation to medicine use. These positive opinions expressed by the participants of the present study can be attributed to their high knowledge on the PV program and ADR reporting. The factors that affect the reporting of ADR in relation to the respondents attitudes studied in the present study included lack of time and non-remuneration. When respondents were asked whether non-remuneration discourages them from reporting ADRs, the pharmacists exhibited more positive attitudes $(60.3 \%)$ by disagreeing compared to the response from the doctors (56.7\%) and the nurses (45\%). It can thus be said that though they are knowledgeable about PV and ADR reporting, majority of the nurses are more likely to report ADRs when there is a motivational incentives attached to the exercise. In the present study also, lack of time was found to be one of the major negative attitudes of the participants towards ADR reporting. Only as low as $36.7 \%$ and $39 \%$ of the doctors and the nurses respectively, dis agreed that lack of time to report ADRs discourages them from reporting. Majority of them however saw lack of time to report as being one of the main challenges to ADR reporting. In earlier studies, lack of time to report ADRs has also been cited as one of the major hindrances to passive pharmacovigilance $[8,11,12]$.

\section{Summary}

The Pharmacovigilance (PV) program was started in Ghana in 2001. Healthcare professionals have been the major reporters of Adverse Drug Reactions (ADRs) since the inception of the medicine safety monitoring system in Ghana. Under reporting have however been reported to be one of the major challenges to the success of the program. The study was carried out at the Volta Regional Hospital in Ho in the Volta Region of Ghana to evaluate knowledge and attitudes towards pharmacovigilance practices among the Healthcare Professionals (HCPs) at the hospital. The KAP survey model was employed to assess the knowledge, attitude and practices of the participants towards the PV program. The participants included in the study were HCPs that have permanently practiced for more than a year and have direct contact with patients in relation to medicine use and are in positions to report ADRs. A total of 145 respondents were involved in the study and the response rate to the questionnaire was $100 \%$. Out of the total number of respondents, 30 were doctors, 15 were pharmacists (including pharmacy technologists and dispensing technicians) and 100 were nurses. Majority (92) of the respondents were females with the rest (53) being males. The findings revealed that, majority of all cadres of respondents were knowledgeable about PV and ADR reporting. Majority responded correctly to the questionnaire items that assessed the knowledge levels. Most of the respondents also exhibited positive attitudes to PV. Though majority of the respondents exhibited good knowledge and right attitude to the program, their practice levels were however found to be low especially among the nurses and the doctors. Majority of the respondents responded yes to having challenges to the reporting of ADRs. The challenges displayed include non-availability of the responding forms, patients' noncooperation, lack of time to report and not knowing how to report ADRs. Respondents went on to suggest the following as measures to improve upon PV activities at the hospital: public education on the need to report ADRs, periodic hands- on sensitization of HCPs on $\mathrm{PV}$ and ADR reporting and reminding patients to come for regular check-ups, inter-facility peer review on PV, prompt feedback from the National PV Centre after assessment of forms, assigning specific people to be in charge of pharmacovigilance, making ADR reporting forms available at all times, development of a system to encourage patient self-reporting, capacity building of healthcare professionals on ADR reporting, regular visit to healthcare facilities by the National Centre to encourage ADR detection, monitoring, and reporting by HCPs.

\section{Conclusion}

The percentage average of knowledge of the respondents on PV was found to be $88.8,92.2$ and $78 \%$ among the doctors, pharmacists and nurses respectively which can be attributed to the fact that more of the sensitization and training on the PV program by the country's National Pharmacovigilance Centre has over the years been carried out in most Government health facilities [20-39].

Positive attitudes are required to couple high knowledge levels among HCPs in order to practice PV and ADR reporting at the health facility. Such positive attitudes include the view of the medicine safety monitoring system as an ethical and professional thing to do as well as being part of the health care delivery system. The respondents in the present study generally exhibited positive attitudes towards PV and ADR reporting. The percentage averages of positive attitudes recorded in the study are $72 \%$ for the doctors, $83.8 \%$ for the pharmacists and 
Citation: Amedome SN, Dadson BA (2017) Pharmacovigilance Practices: Knowledge and Attitudes among the Healthcare Professionals at the Volta Regional Hospital of Ghana. J Pharmacovigil 5: 229. doi:10.4172/2329-6887.1000229

$68.2 \%$ for the nurses. However, lack of time to report ADRs was recorded in the study to be a negative attitude among majority of the respondents with only as low as $36.7 \%$ and $39 \%$ of the doctors and the nurses disagreeing that lack of time to report ADRs discourage them from reporting. It is believed that such negative attitudes can be changed when the HCP is trained and encouraged to consider medicine safety monitoring system as part of the daily clinical practice.

\section{Recommendations}

Based on the study findings and the conclusions drawn, the following recommendations are made. It is recommended that medicine safety monitoring committee be established and person(s) be appointed to be in-charge of pharmacovigilance at the hospital, who must be given capacity building training on PV to foster an effective monitoring and assessment mechanism of PV activities at the hospital.

Also, periodic training and refresher programs must be organized for healthcare professionals at the hospital. The trainings should centre on the national reporting procedure for ADRs, requirements for an optimum functional PV system, the essential roles of the HCP in the PV program and the use of the reporting forms. Other areas that such educational interventions should concentrate on include training of the healthcare professionals on how to carry out identification, detection and monitoring of patients experiencing an ADR.

Since the PV activities require patient cooperation, there is also the dire need to create increased public awareness about the medicine safety monitoring system in place in the country. Such public awareness programs can take the form of public education and talk shows on radio and television to highlight the essential aims and benefit of PV as well as the need for increased patient cooperation. Promotional adverts can also be run on radio, television, internet, SMS alerts and in the print media.

\section{References}

1. Ghana National Drug Programme (2004) Ghana national drug policy. Accra Ghana: Author.

2. Mann RD, Andrews E (2007) Pharmacovigilance. John Wiley and Sons Ltd., The Atrium, Southern Gate, Chichester, Sussex PO19 8SQ, England.

3. The World Health Organization (WHO)(2002) The importance of pharmacovigilance: safety monitoring of medicinal products.

4. Food and Drugs Authority (2015) Druglense Newsletter. Accra, Ghana.

5. Green CF, Mottram DR, Rowe PH, Pirmohamed M (2001) Attitudes and knowledge of hospital pharmacists to adverse drug reaction reporting. $\mathrm{Br} \mathrm{J}$ Clin Pharmacol 51: 81-86

6. Belton KJ, Lewis SC, Payne S, Rawlins MD, Wood SM (1995) Attitudinal survey of adverse drug reaction reporting by medical practitioners in the United Kingdom. Br J Clin Pharmacol 39: 223-226.

7. Bateman DN, Sanders GL, Rawlins MD (1992) Attitudes to adverse drug reaction reporting in the Northern Region. Br J Clin Pharmacol 34: 421-426.

8. Chopra D, Wardhan N, Rehan HS (2011) Knowledge, attitude and practices associated with adverse drug reaction reporting amongst doctors in a teaching hospital. Int J Risk Saf Med 23: 227-232.

9. Okechukwu CR, Odinduka SO, Ele GN, Okonta MJ (2013) Awareness, attitude, and practice of pharmacovigilance among health care professionals in nigeria: survey in a teaching hospital. Int J Hos Res 2: 99-108.

10. Palaian S, Ibrahim MI, Mishra P (2011) Health professionals' knowledge, attitude and practices towards pharmacovigilance in Nepal. Pharm Prac 9 : 228-235.

11. Granas AG, Buajordet M, Stenberg-Nilsen H, Harg P, Horn AM (2007) Pharmacists' attitudes towards the reporting of suspected adverse drug reactions in Norway. Pharmacoepidemiol Drug Saf 16: 429-434.
12. Su C, Ji H, Su Y (2010) Hospital pharmacists' knowledge and opinions regarding adverse drug reaction reporting in Northern China. Pharmacoepidemiol Drug Safety 19: 217-222.

13. Sabblah GT, Akweongo P, Darko D, Dodoo ANO, Sulley AM (2014) Adverse drug reaction reporting by doctors in a developing country: a case study from Ghana. Ghana Med J 48: 189-193.

14. Passier A, ten Napel M, van Grootheest K, van Puijenbroek E (2009) Reporting of adverse drug reactions by general practitioners. Drug Saf 32: 851-858.

15. Ting KN, Stratton-Powell DM, Anderson C (2010) Community pharmacists views on adverse drug reactions reporting in Malaysia: a pilot study. Pharm World Sci 32: 339-342.

16. Vessal G, Mardani Z, Mollai M (2009) Knowledge, attitudes, and perceptions of pharmacists to adverse drug reaction reporting in Iran. Pharmacy World Sci 31: $183-187$

17. Rehan HS, Vasudev K, Tripathi CD (2002) Adverse drug reaction monitoring: knowledge, attitude and practices of medical students and prescribers. Nat Med J Ind 15: 24-26.

18. Aziz Z, Siang TC, Badarudin NS (2007) Reporting of adverse drug reactions: predictors of under-reporting in Malaysia. Pharmacoepidemiol Drug Saf 16 223-228.

19. Li Q, Zhang SM, Chen HT, Fang SP, Yu X, et al. (2004) Awareness and attitudes of healthcare professionals in Wuhan, China to the reporting of adverse drug reactions. Chinese Med J 117: 856-861.

20. Gavaza P, Brown CM, Khoza S (2010) Texas pharmacists' opinions on reporting serious adverse drug events to the Food and Drug Administration: a qualitative study. Pharm World Sci 32: 651-657.

21. Belton KJ, European Pharmacovigilance Research Group (1997) Attitude survey of adverse drug-reaction reporting by health care professionals across the European Union. Eur J Clin Pharmacol 52: 423-427.

22. Bless C, Higson SC, Kagee A (2006) Fundamentals of social research methods: An African perspective. Juta and Company Ltd.

23. Deepa (2015) Evaluation of awareness, knowledge, attitude and practices of nursing students on monitoring and reporting of adverse drug reactions in a tertiary care hospital. World J Pharm Res 4: 1361-1371.

24. Desai CK, lyer G, Panchal J, Shah S, Dikshit RK (2011) An evaluation of knowledge, attitude, and practice of adverse drug reaction reporting among prescribers at a tertiary care hospital. Perspect Clin Res 2: 129-36.

25. Ekman E, Bäckström M (2009) Attitudes among hospital physicians to the reporting of adverse drug reactions in Sweden. Eur J Clin Pharmacol 65: 43-46.

26. Bajaj K, Jagminder, Kumar R (2013) A survey on the knowledge, attitude and the practice of pharmacovigilance among the health care professionals in a teaching hospital in northern India. J Clin Diag Res 7.

27. Hasford J, Goettler M, Munter KH, Müller-Oerlinghausen B (2002) Physicians' knowledge and attitudes regarding the spontaneous reporting system for adverse drug reactions. J Clin Epidemiol 55: 945-950.

28. Inman WH (1996) Attitudes to adverse drug reaction reporting. $\mathrm{Br} \mathrm{J}$ Clin Pharmacol 41: 434-435.

29. Jarernsiripornkul N, Krska J, Pongmanachai M, Nasritha N (2009) Hospital pharmacists' activities and attitudes regarding the Thai safety monitoring program for new drugs. Pharmacoepidemiol Drug Saf 18: 837-841.

30. Khan TM (2013) Community pharmacists' knowledge and perceptions about adverse drug reactions and barriers towards their reporting in Eastern region, Alahsa, Saudi Arabia. Ther Adv Drug Saf 4: 45-51.

31. Kohn LT, Corrigan JM, Donaldson MS (2000) To err is human: building a safer health system. Nat Acad Press, Washington.

32. Kulkarni MD, Baig MS, Chandaliya KC, Doifode SM, Razvi SU, et al. (2013) Knowledge, attitude and practice of pharmacovigilance among prescribers of government medical college and hospital, Aurangabad (Maharashtra). Int J Pharm Therapeut 3: 10-18.

33. Pérez García M, Figueras A (2011) The lack of knowledge about the voluntary reporting system of adverse drug reactions as a major cause of underreporting: direct survey among health professionals. Pharmacoepidemiol Drug Saf 20 1295-1302. 
Citation: Amedome SN, Dadson BA (2017) Pharmacovigilance Practices: Knowledge and Attitudes among the Healthcare Professionals at the Volta Regional Hospital of Ghana. J Pharmacovigil 5: 229. doi:10.4172/2329-6887.1000229

Page 9 of 9

34. Ramesh M, Parthasarathi G (2009) Adverse Drug Reactions Reporting: Attitudes and Perceptions of Medical Practitioners. Asian J Pharm Clin Res 2: $10-14$

35. Strengthening Pharmaceutical Systems Program (2011) Safety of medicines in sub-saharan africa: assessment of pharmacovigilance systems and their performance. submitted to the us agency for international development by the Strengthening Pharmaceutical Systems (SPS) Program. Arlington, VA: Management Sciences for Health.

36. Vora MB, Barvaliya M (2014) Knowledge, attitude and practices towards pharmacovigilance and adverse drug reactions in health care professional of tertiary care hospital, Bhavnagar. Int J Pharma Sci Res 5: 820-826.
37. The World Health Organization (WHO) (1972) International drug monitoring the role of national centres. Technical Report Series No 498.

38. The World Health Organization (WHO) (2004) Pharmacovigilance: ensuring the safe use of medicines. WHO Policy Perspectives on Medicines.

39. Wilson RM, Michel P, Olsen S, Gibberd RW, Vincent C, et al. (2012) Patient safety in developing countries: retrospective estimation of scale and nature of harm to patients in hospital. BMJ 344: e832. 